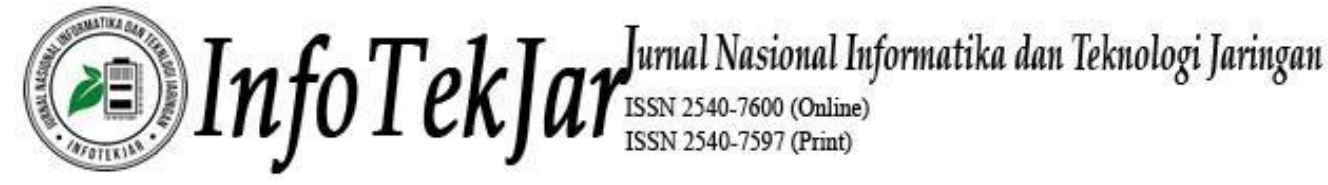

\section{PERANCANGAN SISTEM INFORMASI WEBSITE SENI BUDAYA PRABUMULIH PADA DINAS PENDIDIKAN DAN KEBUDAYAAN KOTA PRABUMULIH}

\author{
Andi Christian \\ STMIK Prabumulih \\ Jl. Patra No 50 Kelurahan Sukaraja Kecamatan Prabumulih Selatan, 31111, Indonesia \\ Andichristian918@gmail.com
}

\begin{abstract}
Abstrak - Perkembangan teknologi informasi di zaman modernisasi ini sudah banyak merubah gaya hidup manusia disegalah bidang baik instasi swasta dan pemerintah dan masyarakat umum. Hal ini dapat menjadi salah satu unsur seni budaya Prabumulih mulai ditinggalkan oleh masyarakat akibat adanya globalisasi teknologi informasi. Namun hal tersebut dapat juga memberikan dampak positif apabila kita memanfaatkan teknologi contohnya internet sebagai media untuk mempromosikan kembali seni buya kota Prabumulih kepada masyarakat luas. Dari penelitian ini akan menghasilkan sebuah rancangan Website yang akan mempermudah masyarakat dalam mencari informasi terkait seni budaya Prabumulih melalui jaringan internet yang bebas diakses kapanpun, dimanapun dengan cepat dan akurat. Selain itu juga dapat menjadi sarana promosi untuk memperkenalkan kebudayaan Prabumulih kepada masyarakat luas bahkan seluruh dunia.
\end{abstract}

Kata kunci: Website, Sistem informasi,Seni Budaya Prabumulih

\section{PENDAHULUAN}

Sebagaimana tercantum dalam UUD 1945 pasal 32 yang menjelaskan bahwa (1) memajukan kebudayaan nasional Indonesia di tengah peradaban dunia dengan menjamin kebebasan masyarakat dalam memelihara dan mengembangkan nilai-nilai budayanya. (2) Negara menghormati dan memelihara bahasa daerah sebagai kekayaan budaya nasional. Akan tetapi, perkembangan kebudayaan dan gaya hidup modernisasi saat ini menyebabkan lemahnya budaya bangsa. Dirgantara (2012) menyatakan bahwa banyak kebudayaan bangsa kita yang tidak kita kenal, kita baru merasa memiliki setelah kebudayaan tersebut diakui sebagai buah karya bangsa lain. Untuk itu dalam upaya menanamkan, mengembangkan dan memelihara seni budaya diperlukan adanya pendidikan.

Perkembangan teknologi informasi di zaman modernisasi ini sudah banyak merubah gaya hidup manusia disegalah bidang baik instasi swasta dan pemerintah dan masyarakat umum. Hal ini dapat menjadi salah satu unsur seni budaya Prabumulih mulai ditinggalkan oleh masyarakat akibat adanya globalisasi teknologi informasi. Namun hal tersebut dapat juga memberikan dampak positif apabila kita memanfaatkan teknologi contohnya internet sebagai media untuk mempromosikan kembali seni buya kota Prabumulih kepada masyarakat luas bahkan seluruh dunia dapat mengakses informasi tersebut melalui internet. Saat ini hanya terdapat sedikit website yang dibangun untuk memperkenalkan suatu seni budaya, terutama seni budaya kota Prabumulih. Perancangan Website seni budaya prabumulih merupakan salah satu upaya yang dapat dilakukan untuk membantu pemerintah kota prabumulih dalam menghidupkan kembali seni budaya yang ada di kota prabumulih kepada masyarakat luas agar seni budaya yang ada di kota prabumulih tetap dapat dilestarikan. Melihat semakin berkurangnya pemahaman masyarakat tentang seni budaya Prabumulih.

\section{METODE PENELITIAN}

Penelitian ini menggunakan metode deskriptif kualitatif. Sedangkan penelitian deskriptif kualitatif ini bertujuan untuk mendeskripsikan apa-apa yang saat ini berlaku. Di dalamnya terdapat upaya mendeskripsikan, mencatat, analisis dan menginterpretasikan kondisi yang sekarang ini terjadi atau ada. Dengan kata lain penelitian deskriptif kualitatif ini bertujuan untuk memperoleh informasi- informasi mengenai keadaan yang ada (Sitokdana dan Tanaamah, 2016).

\section{METODE PENGEMBANGAN SISTEM}

Menurut Jogiyanto (2010), metode pengembangan sistem adalah metode prosedur, konsep-konsep pekerjaan dan aturan yang akan digunakan untuk mengembangkan suatu sistem informasi. Pengembangan sistem didefinisikan sebagai sistem informasi berbasis komputer untuk menyelesaikan persoalan (problem) organisasi atau memanfaatkan kesempatan. Model air terjun (waterfall) mengambil kegiatan dasar seperti spesifikasi, pengembangan, validasi dan evolusi serta merepresentasikannya sebagai fase seperti spesifikasi persyaratan, perancangan perangkat lunak, implementasi, pengujian dan seterusnya. . Tahapan model waterfall dapat dilihat pada gambar 1 di bawah ini: 


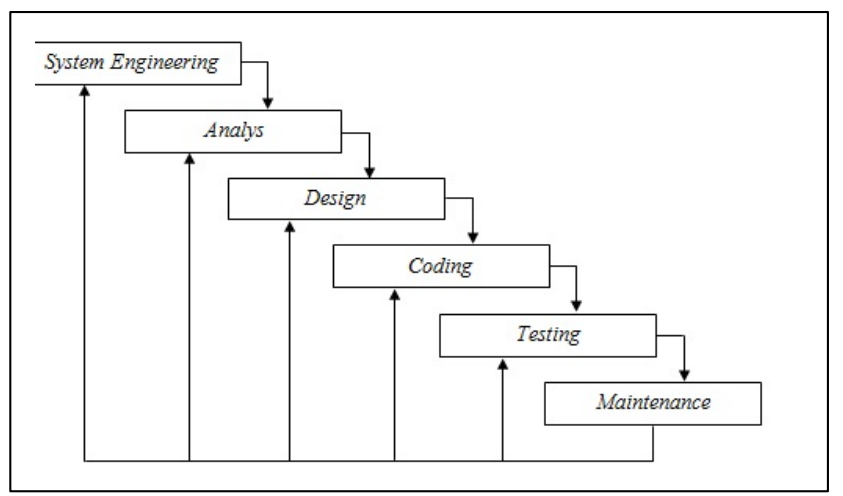

Gbr 1 Model Waterfall

Keterangan menurut gambar diatas alur dari model waterfall sebagai berikut:

1. System Engineering, merupakan bagian awal dari pengerjaan suatu proyek perangkat lunak. Dimulai dengan mempersiapkan segala hal yang dibutuhkan dalam pelaksanaan proyek seperti komputer/laptop, aplikasi yang diperlukan, dokumen, data-data seni budaya Prabumulih, buku, foto dokumentasi dan sebagainya,

2. Analysis, yakni tahapan yang bertujuan untuk memahami sistem yang ada. Dalam analisis ini harus mendapatkan beberapa hal yang dianggap menunjang penelitian seperti mengumpulkan data, wawancara, dan lain-lain untuk diteliti dan diidentifikasi masalah yang ada terkait seni budaya Prabumulih untuk diberikan solusinya,

3. Design, merupakan proses perancangan yang terfokus pada desain pembuatan program perangkat lunak yang akan dibangun meliputi alur kerja sistem, cara pengoprasian sistem dan hasil outputnya dengan menggunakan metode seperti UML (Unified Modeling Language). Tahap pembuatan desain sistem ini didapat dari data yang telah dianalisis,

4. Coding, yaitu menerjemahkan data yang dirancang ke dalam bentuk bahasa pemrograman yang telah ditentukan. Dalam proses ini peneliti menggunakan bahasa pemrograman PHP yang menghasilkan program sesuai desain yang dirancang untuk dapat dijalankan,

5. Testing, merupakan uji coba terhadap sistem atau program yang telah dibuat. Pada tahapan ini peneliti menguji coba hasil program yang dibuat dengan menggunakan browser, dan

6. Maintenance, yaitu penerapan sistem secara keseluruhan disertai pemeliharaan jika terjadi perubahan struktur. baik dari segi software maupun hardware.

\section{ANALISA DAN PERANCANGAN SISTEM}

\section{A. Analisa}

Analisa sistem merupakan suatu tahap pemahaman proses yang bertujuan untuk mengetahui proses apa saja yang terlibat di dalam sistem, bagaimana kerja dari setiap proses yang terlibat didalam sistem dan hubungan suatu proses dengan proses yang lainnya. Dari pemahaman proses tersebut maka dapat dilakukan suatu evaluasi dan usulan terhadap sistem yang ada, untuk dikembangkan lebih lanjut.

\section{B. Perancangan Sistem}

Dalam perancangan desain Website seni budaya Prabumulih, pengunjung dapat mengakses secara langsung halaman web melalui jaringan internet menggunakan laptop, komputer ataupun smartphone. Sedangkan admin bertugas untuk mengelolah Website tersebut melalui laman web admin untuk dapat melakukan update data maupun pemeliharaan.

\section{Use Case Diagram}

Berikut diagram use case yang digunakan dalam Perancangan Website Seni Budaya Kota Prabumulih, dapat dilihat pada gambar 2 dibawah ini:

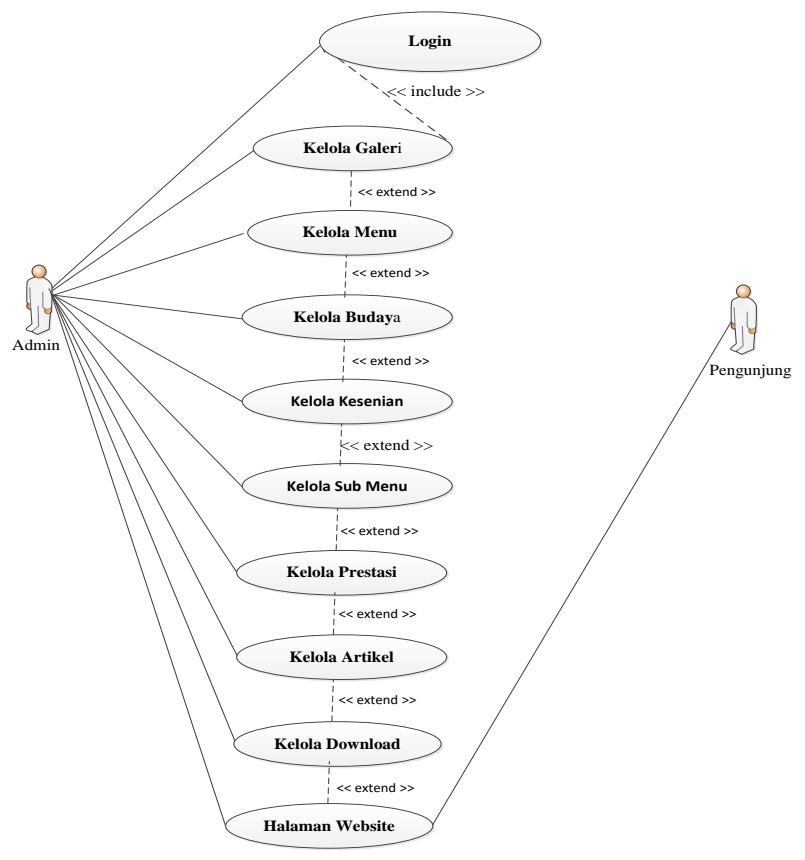

Gbr 2 Use Case Diagram 
2. Class Diagram

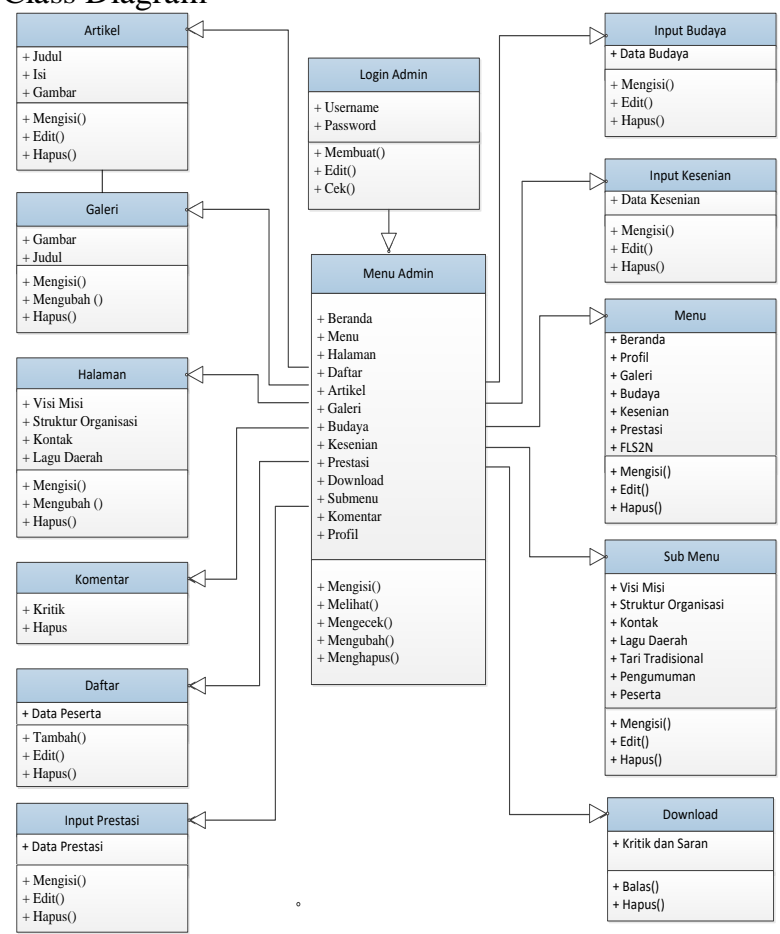

Gbr 3 Class Diagram

\section{HASIL DAN PEMBAHASAN}

Berikut ini tampilan antar muka untuk membuat hasil rancangan sistem ke bentuk tampilan Website, antara lain:

\section{A. Tampilan Halaman Utama Website}

Tampilan halaman utama Website dapat dilihat pada gambar 4 berikut:

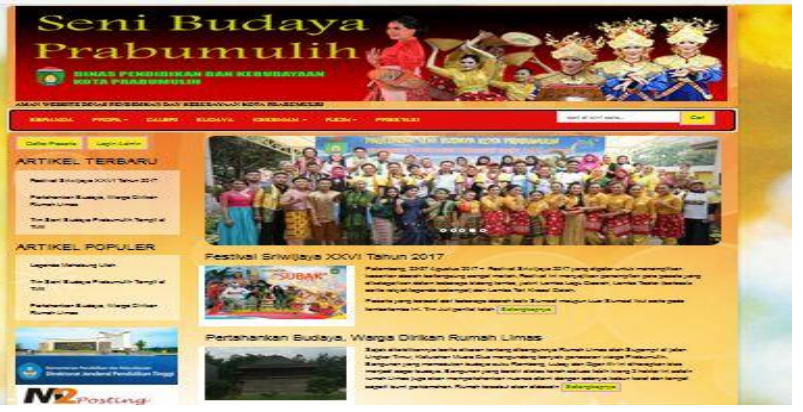

Gbr 4 Tampilan Halaman Utama Website

\section{B. Tampilan Halaman Profil}

Halaman profil pada menu utama Website terdiri dari tiga submenu yaitu visi \& misi, profil dan kontak, seperti gambar 5 dibawah ini:

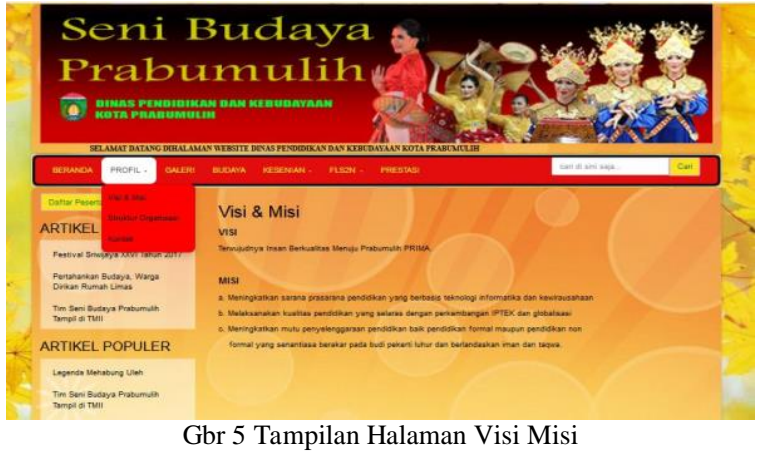

C. Tampilan Halaman Galeri

Tampilan halaman galeri pada halaman utama Website dapat dilihat pada gambar 6 berikut:

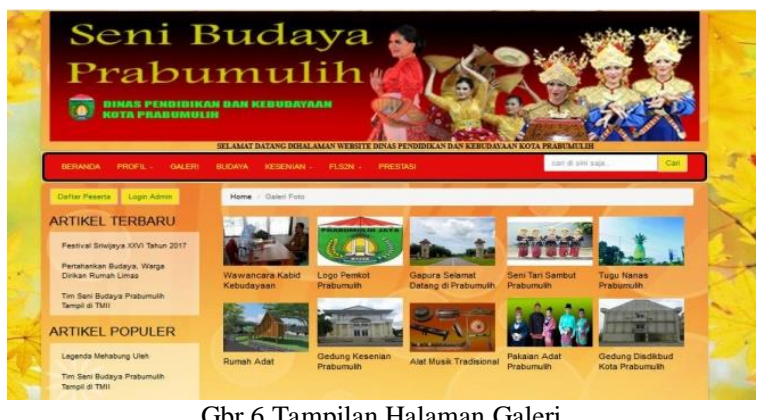

Gbr 6 Tampilan Halaman Galeri

\section{Tampilan Halaman Budaya}

Tampilan halaman budaya pada halaman utama Website, dapat dilihat pada gambar 7 berikut:

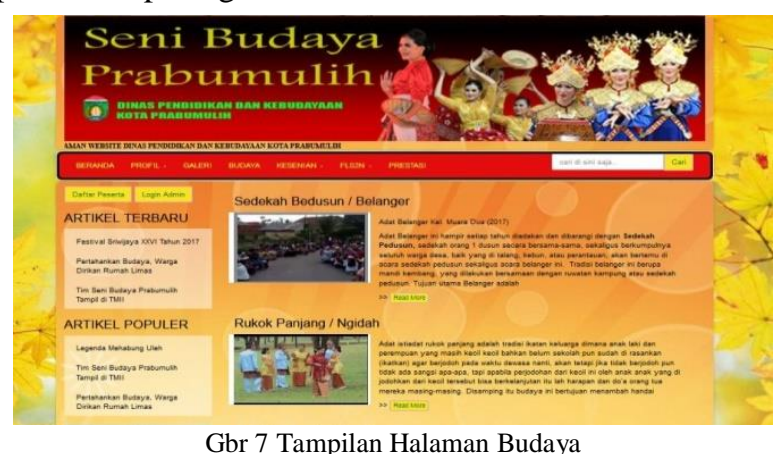

\section{E. Tampilan Halaman Kesenian}

Tampilan halaman kesenian pada halaman utama Website memiliki dua submenu yaitu lagu daerah dan tari tradisional seperti pada gambar 8 berikut: 


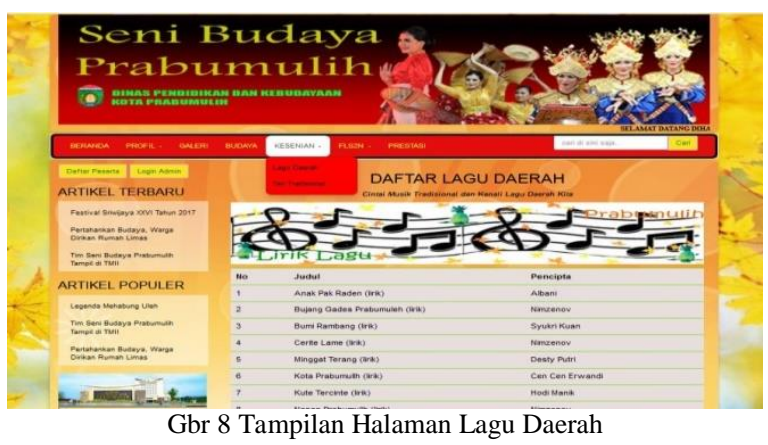

\section{F. Tampilan Halaman FLS2N}

Tampilan halaman FLS2N pada halaman Website memiliki dua submenu yaitu pengumuman dan data peserta, seperti pada gambar 9 berikut:

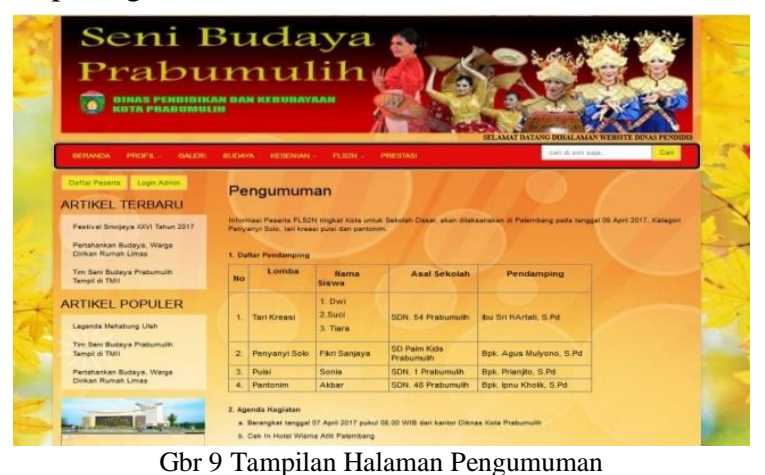

G. Tampilan Halaman Prestasi

Berikut ini adalah tampilan halaman prestasi pada halaman utama Website seperti gambar 10 dibawah ini:

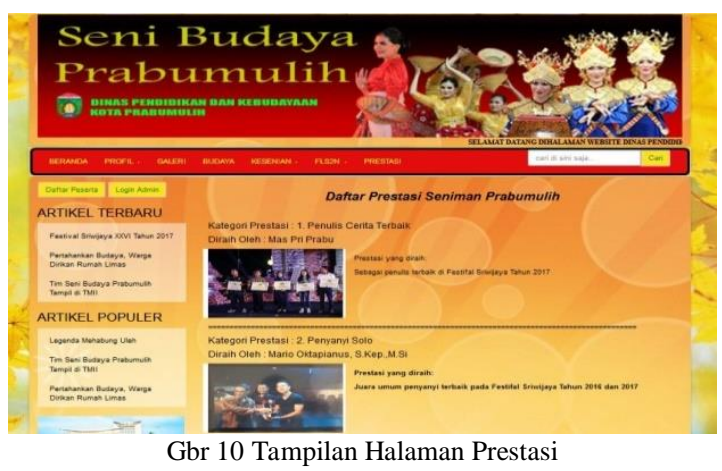

\section{H. Tampilan Halaman Download}

Tampilan halaman download pada halaman utama Website dapat dilihat pada gambar 11 berikut ini:

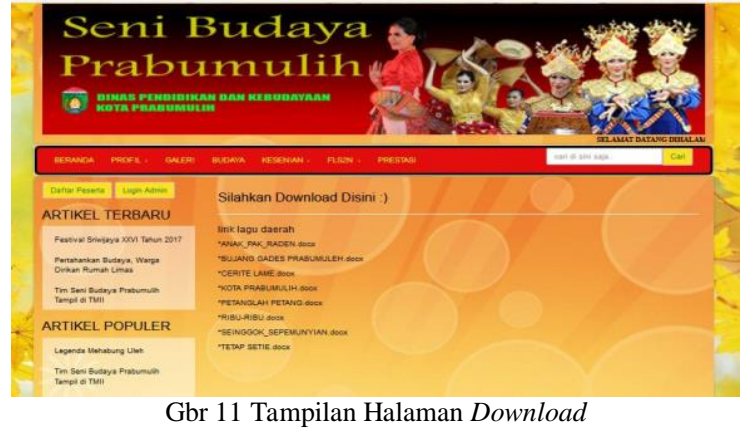

\section{KESIMPULAN}

Dengan adanya website ini saya mengaharapkan dapat membantu pemerintah kota prabumulih dalam meperkenalkan seni buaya yang ada diprabumulih dengan cara memanfaatkan dari kemajuan teknologi di era globalisasi ini dalam hal ini menggunakan jaringan internet sebagai alat atau media yang dapat dimanfaatkan untuk mempromosikan kembali seni budaya kota prabumulih kepada masyarakat luas baik pun masyarkat seluruh dunia yang dapat mengakses informasi tersebut melalui internet.

\section{UCAPAN TERIMA KASIH}

Dengan terlaksananya penelitian ini, maka penulis mengucapkan terima kasih kepada

1. Allah S.W.T atas berkah dan ramatnya juah penelitian ini bisa terlaksana.

2. Ketua STMIK Prabumulih dan Ketua UP2M STMIK Prabumulih yang sudah memberikan kesempatan dan memfasilitasi dalam penelitian ini

3. Kepada rekan-rekan dosen STMIK prabumulih yang telah banyak membantu dalam penyelesaian penelitian ini

4. Kepada TIM Jurnal Nasioanl Informatika dan Teknologi Jaringan (InfoTekjar) yang sudah bersedia dalam penerbitan penelitian ini.

\section{REFERENSI}

[1] Dirgantara, Yuana Agus. 2012. Pelangi Bahasa Sastra dan Budaya Indonesia. Jakarta: Garudhawaca

[2] Jogiyanto, 2010. Analisis dan Desain Sistem Informasi Edisi IV. Yogyakarta: Andi Offset.

[3] Kadir, Abdul. 2013. Buku Pintar Programmer Pemula PHP. Yogyakarta: MediaKom.

[4] Nugroho, Adi. 2010. Perancangan dan Implementasi Sistem Basis Data. Jogyakarta: Andi.

[5] Sitokdana, Melkior dan Tanaamah Andeka Rocky. 2016. "Strategi Pembangunan E-Culture di Indonesia"dalam Jurnal Teknik Informatika dan Sistem Informasi Vol 2 No 2 Agustus 2016, hlm.139.

[6] Undang-Undang Dasar Republik Indonesia Nomor 23 Tahun 1992 tentang Pendidikan dan Kebudayaan. 